Research Article

\title{
Statistical Analysis of Flame Oscillation Characterization of Oxy-Fuel in Heavy Oil Boiler Using OH Planar Laser-Induced Fluorescence
}

\author{
Xin Yu, ${ }^{1,2}$ Zhen Cao, ${ }^{1,2}$ JiangBo Peng $\left(\mathbb{D},{ }^{1,2}\right.$ Yang Yu, ${ }^{1,2}$ Guang Chang, ${ }^{1,2}$ Yufei Ma, ${ }^{1,2}$ \\ XiaoHui Li, ${ }^{1,2}$ Chaobo Yang, ${ }^{1,2}$ and ZhiQiang Wang ${ }^{3}$ \\ ${ }^{1}$ National Key Laboratory of Science and Technology on Tunable Laser, Harbin Institute of Technology, Harbin 150080, China \\ ${ }^{2}$ Institute of Opt-Electronics, Harbin Institute of Technology, Harbin 150080, China \\ ${ }^{3}$ School of Energy and Power Engineering, Shandong University, Jinan 250000, China
}

Correspondence should be addressed to JiangBo Peng; pengjiangbo_2004@126.com

Received 20 March 2019; Accepted 12 June 2019; Published 2 July 2019

Academic Editor: Arnaud Cuisset

Copyright ( 2019 Xin Yu et al. This is an open access article distributed under the Creative Commons Attribution License, which permits unrestricted use, distribution, and reproduction in any medium, provided the original work is properly cited.

\begin{abstract}
The present work investigated the flame structures and oscillations of oxy-fuel combustions in a heavy oil boiler using $\mathrm{OH}$ planar laser-induced fluorescence imaging. Combustion instabilities, such as flame oscillation and combustion fluctuation, can assess the performance of an industrial burner in the boiler. The peak position variation in $\mathrm{OH}$ concentration was associated with the change of the reaction zone that corresponded with the fluctuation of the heat-release zone in the combustion chamber, which provides a valuable reference for the design of the combustion chamber. The experimental results suggest that the phenomenon of stratified flame combustion is related to the characteristic of flame oscillation. The substitution of $\mathrm{N}_{2}$ with $\mathrm{CO}_{2}$ will not significantly influence the flame oscillation frequency but increases the number of flame surface. $\mathrm{As}_{2}$ concentration increased in the $\mathrm{O}_{2} / \mathrm{CO}_{2}$ atmosphere, the phenomenon of stratified flame combustion disappeared, and the flame presented an island-like structure. The bimodal oscillation of the combustion center was demonstrated by means of the probability density method; $\mathrm{CO}_{2}$ played a role in the extension of the combustion center. The combustion fluctuation of inner regions was quantitatively described; $\mathrm{CO}_{2} \mathrm{could}$ maintain interregional stabilization to some extent. Compared with traditional measurement methods, PLIF technology has great advantages in evaluating burner performance and optimizing the design of the combustion chamber.
\end{abstract}

\section{Introduction}

In the context of energy saving and emission reduction, heavy oil, which has the advantages of abundant reserves and low costs, has been the focus of much attention [1-3]. The oxy-fuel combustion process has been proposed as a promising technology for controlling $\mathrm{CO}_{2}$ emissions, thus presenting an important option to address the environmental issues [4-6]. Therefore, the combustion system of heavy oil is combined with oxy-fuel combustion process in order to reduce carbon dioxide emissions while offering a more efficient use of heavy oil resources [7]. However, the successful implementation of $\mathrm{O}_{2} / \mathrm{CO}_{2}$ technology in heavy oil boilers requires a comprehensive understanding of the changes caused by the replacement of $\mathrm{N}_{2}$ with $\mathrm{CO}_{2}$ in the combustion atmosphere. In addition, the consequent stability problems of the combustion system also cannot be ignored [8]. In view of the performance evaluation of industrial-type burners, combustion instabilities during the combustion process are important for assessing the quality of the burners.

Previous experience with the study of industrial combustors suggests that combustion instability may exist in scramjet engines and gas turbines [9-12]. Both the type of fuel and the injection mechanism have an impact on acoustic motion and flame oscillation. The characteristics of frequency oscillation, both experimentally and analytically, were investigated [13-15]. Combustion instabilities 
including flame oscillation and combustion fluctuation are also of great significance in the combustion efficiency and even the safety of combustion system, although the problem of heavy oil boilers has not been recognized and explored thoroughly. The research on the instability of combustion system published mainly focuses on the measurement of temperature and pressure. The traditional measurement methods are implemented by means of temperature and pressure sensor with high precision [16-18]. However, due to the limitation of installation positions, the spatial resolution of the measurement is low. At present, modern optical measurement techniques are applied to the combustion experiments increasingly, achieving the measurement of many important combustion parameters such as concentration, velocity, and temperature [19-21]. High-speed PLIF visualization measurement technology possesses the characteristics of high spatial and temporal resolution, which can not only present the spatial structure of flame but also provide the time characteristic information of flame. The peak position variation in $\mathrm{OH}$ concentration was associated with the change of the reaction zone that corresponded with the fluctuation of the heat-release zone in the combustion chamber. The flame fluctuation can be tracked in real time, so combustion instability reflected by flame fluctuation can be investigated without spatial and temporal limitations.

Over recent years, the high-speed PLIF (planar laserinduced fluorescence) measurement system has been widely used in laboratory small-scale combustion devices [22, 23], but its application in industrial combustors bench, such as scramjet engines and boilers, is still rare [24, 25]. The harsh bench test environment and high requirements on the performance of laser, detector, and optical system limit its engineering applications. Considering complex test environment, a set of high-speed PLIF measurement system with high reliability and environmental adaptability is independently developed. This system consisted of modular design, temperature, and humidity control and vibration isolation device possesses extremely high environmental adaptability.

The aim of this paper is to report the characteristics of flame structures and oscillations under the oxy-fuel combustion conditions. In the experiment, the flame structure of oxy-fuel combustion of heavy oil was reported applying a $400 \mathrm{~Hz}$ OH-PLIF. In our previous ignition experiments of heavy oil combustion in the boiler, including autoignition and forced ignition, the temporal resolution of $400 \mathrm{~Hz}$ was sufficient to track the temporal evolution of the flame in boilers. A deep understanding of the combustion instabilities is beneficial to understand comprehensively the operating performance of industrial burner, especially providing a valuable reference for boiler design.

\section{Experiment Details}

2.1. PLIF Measurement Apparatus. A schematic diagram for $\mathrm{OH}$-PLIF measurements is shown in Figure 1, as previously described in [26]. The laser system consisted of a pulsed Nd: YAG laser and a dye laser with a frequency-doubling BBO crystal. The second harmonic $(\lambda=532 \mathrm{~nm})$ of the Nd:YAG laser was used to pump the dye laser with rhodamine 590. For the excitation of $\mathrm{OH}$ radical, $\mathrm{Q}_{1}(8)$ line of $A^{2} \sum^{+}-X^{2} \prod(1,0)$ transition at $283.553 \mathrm{~nm}$ was adopted to reduce temperature dependence of the fluorescence signal. It is particularly emphasized here that the harsh bench test environments require the measurement system to have good environmental adaptability. In the laboratory environment, temperature and humidity are better controlled and no dust affects. However, in the bench test environment, high temperature and humidity strongly affect the stable operation of the PLIF measurement system. Specifically, the high temperature can affect thermal effects of laser crystal and reduction of frequency-doubling efficiency, and the high humidity may cause crystal deliquescence. In addition, the fluctuation of laser energy and drift of laser wavelength are also caused by complex test environment. The pumping source was developed independently for the PLIF system to overcome complex experimental environment, including moisture proof and antivibration. The optics consisted of a concave lens $(f=-8 \mathrm{~mm})$, collimating lens $(f=240 \mathrm{~mm})$, and focus lens $(f=800 \mathrm{~mm})$. The sheet forming optics generated a $10.5 \mathrm{~cm}$ laser sheet, and the sheet reaching the observation window was nearly $12.3 \mathrm{~cm}$. A large scale of laser sheet can provide enough visualization area of radicals as a foundation of studying combustion fluctuation.

Considering typically fluorescing components, interferences from soot and Mie scattering from the oil spray can be blocked by the combination of simrock 315/15 and UG11 mounted in front of the ICMOS camera. To minimize contributions of $\mathrm{OH}^{*}$ chemiluminescence and flame luminosity, the detection gate was set to $30 \mathrm{~ns}$. Postprocessing included off-resonant background subtraction, a correction of the inhomogeneous laser sheet profile, and pulse-to-pulse energy variation. As a result, the signals from PLIF images correspond to the $\mathrm{OH}$ radical emission. Concentrations of $\mathrm{OH}$ radicals can be demonstrated qualitatively by $\mathrm{OH}$ fluorescence signals. In the paper, the short-time fast Fourier transform (FFT) revealed the frequency-domain characteristics of flame oscillations, and the statistical probability density method was applied to study interregional combustion fluctuation. The statistical sample extracted from timeresolved sequences of $\mathrm{OH}-\mathrm{PLIF}$ images. For each transient image, the position where the maximum $\mathrm{OH}$ intensity occurs was used to represent high $\mathrm{OH}$ concentration position at that time; meanwhile, the mean $\mathrm{OH}$ intensity in a given region corresponds to the combustion state of the region.

2.2. Flame Conditions. The oxy-fuel combustion system refers to the work of Wang et al. [7]. The oxy-fuel experimental conditions are shown in Table 1. The excess air coefficient is the ratio of the practical oxygen supplement to the theoretical oxygen consumption. In addition, the experiment burner is a commercial burner, whose model was RIELLO40-G10LC (RIELLO, Legnago, Italy). The maximum output is $2.5 \mathrm{GPH}(10 \mathrm{~kg} / \mathrm{h})$. The jet was a solid nozzle (Steinen S) with an output of $1.0 \mathrm{GPH}(3.73 \mathrm{~kg} / \mathrm{h})$, and the atomization angle was 60. The oil pump pressure was 12 bars. In the experiment, only the turbulent flame 


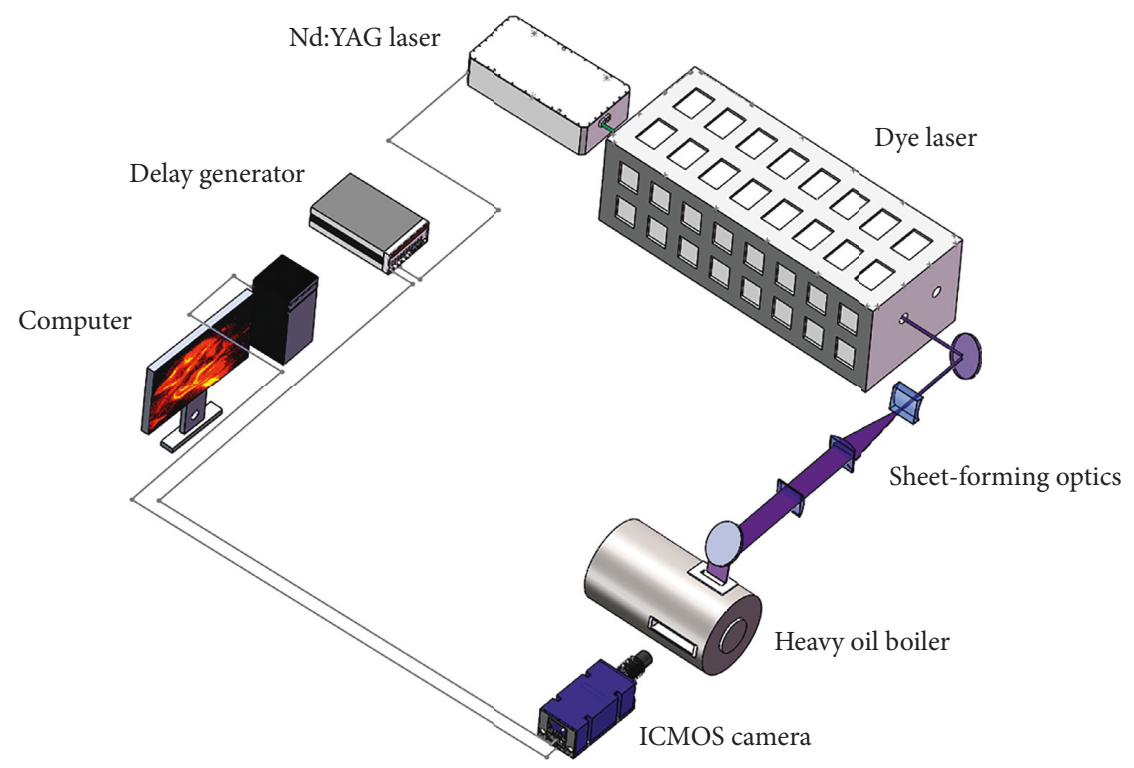

FIGURE 1: Experimental setup schematic diagram.

TABle 1: Oxy-fuel experimental conditions.

\begin{tabular}{lcccccr}
\hline \multirow{2}{*}{ Condition } & \multirow{2}{*}{$\mathrm{O}_{2}$ concentration } & Coefficient of excess air $\alpha$ & \multicolumn{3}{c}{ Composition of gas supply (L/min) } \\
& & & Air & $\mathrm{O}_{2}$ & $\mathrm{CO}_{2}$ & Total gas flow \\
\hline $\mathrm{A} 1$ & 33 & 1.652 & 573 & 103 & 676 \\
$\mathrm{~A} 2$ & 33 & 1.652 & & 223 & 453 & 676 \\
$\mathrm{~A} 3$ & 37 & 1.852 & & 250 & 426 & 676 \\
\hline
\end{tabular}

structures involving the oil-gas combustion process attracted our attention to assess the application of an industrial burner in the boiler and optimize the design of the combustion chamber.

\section{Results and Discussion}

3.1. Flame Oscillation. Experiments were conducted to study the flame oscillation characteristic in the heavy oil boiler under three oxy-fuel combustion conditions. In terms of flame structure, the flame surface exhibited relatively large differences, as shown in Figures 2(a)-2(c). In the $\mathrm{O}_{2} / \mathrm{N}_{2}$ atmosphere, the phenomenon of stratified flame combustion was investigated, which may play an important role in stabilizing combustion. In Figure 2(b), using $\mathrm{CO}_{2}$ instead of $\mathrm{N}_{2}$ in the air as the diluent, it is interesting to find that the number of the flame surface increased and the combustion zone was clearly expanded. As mentioned earlier, spray combustion creates a turbulent environment in the combustion chamber. The flame is not continuous during the turbulent combustion process; instead, it is a process comprising extinction and reignition [27]. The number of the flame surface could strengthen the process of heat and mass and then improve combustion stability. As the concentration of $\mathrm{O}_{2}$ increased in the $\mathrm{O}_{2} / \mathrm{CO}_{2}$ atmosphere, the phenomenon of stratified flame disappeared and the flame presented an island-like structure, as is shown in Figure 2(c).
In order to further study flame oscillation characteristic in the whole combustion process, time-resolved sequences of $\mathrm{OH}$-PLIF images were acquired and the normalized mean $\mathrm{OH}$ signals were extracted as is shown in Figure 3(a). For oxy-fuel combustion condition A1, intermittent drops and jumps in the signal are demonstrated. The conditions A2 and A3 are similar to A1, so for brevity they are omitted here. Figure 3(b) shows the frequency power spectral of the oscillating $\mathrm{OH}$ signals. The low frequency oscillation ranging over $0-50 \mathrm{~Hz}$ exists for both conditions $\mathrm{A} 1$ and $\mathrm{A} 2$, while the amplitude of the latter is slightly lower than the former. For condition A3, there is no dominant frequency in the $0-200 \mathrm{~Hz}$ range. The behavior of self-excited oscillating flame may be influenced by the presence of soot under the higher $\mathrm{O}_{2}$ concentration atmosphere [17].

3.2. Combustion Fluctuation. There is rather strong $\mathrm{OH}$ intensity at the flame surface and high temperature. Heat and mass are transferred into the surrounding gas increasing the temperature and decreasing the density, which resulted in a longitudinal density gradient in the combustion chamber. In that case, a vortex structure is formed and extrudes the flame surface, and then flame fluctuation is generated accordingly. The generated vortex separates the flame from the surrounding gas, slows down the diffusion, and lengthens the flame. As a result, the flame is burning away from the nozzle, so the occurrence position of maximum $\mathrm{OH}$ intensity appears far from the nozzle. On the 

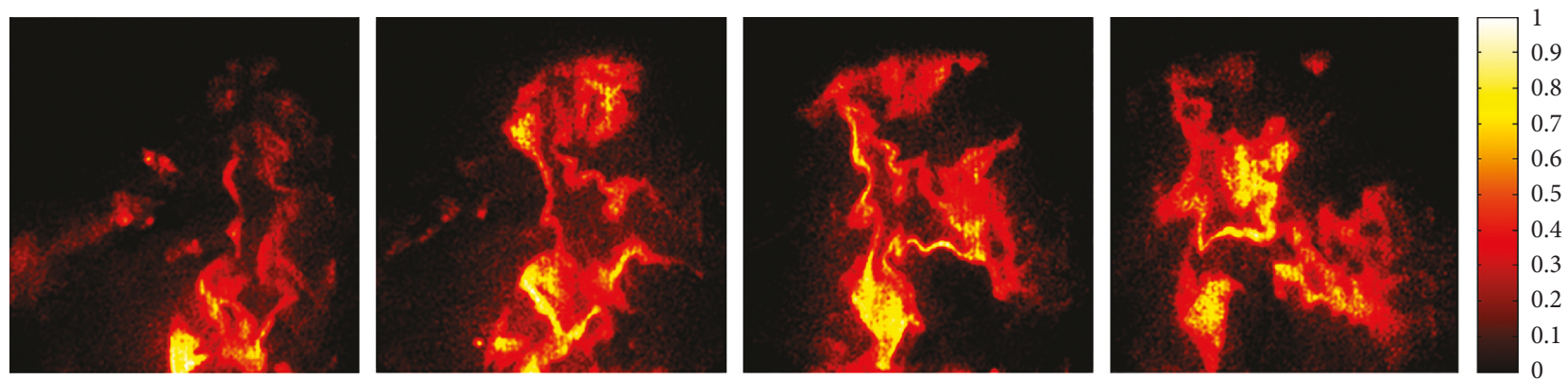

(a)
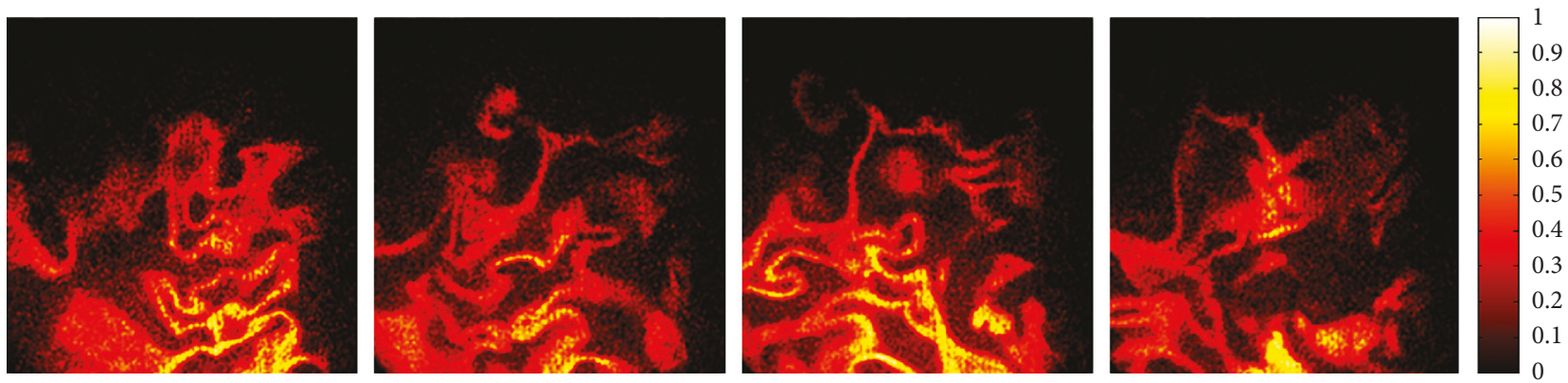

(b)
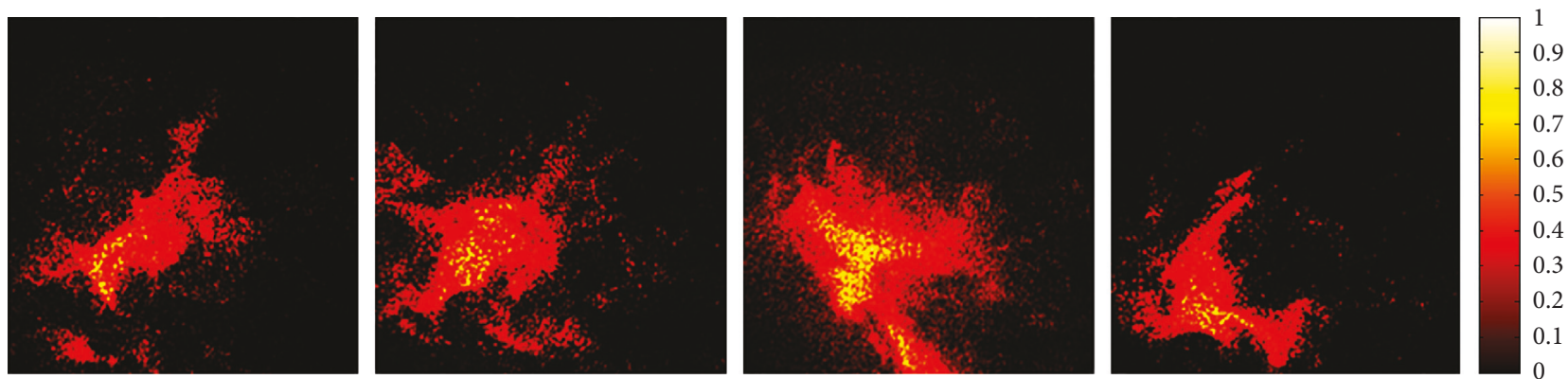

(c)

Figure 2: Selected sequences of OH-PLIF images. (a) In the $\mathrm{O}_{2} / \mathrm{N}_{2}$ atmosphere, the oxygen concentration is $33 \%$ corresponding to the condition $\mathrm{A} 1$; (b) in the $\mathrm{O}_{2} / \mathrm{CO}_{2}$ atmosphere, the oxygen concentration is $33 \%$ corresponding to the condition $\mathrm{A} 2$; (c) in the $\mathrm{O}_{2} / \mathrm{CO}_{2}$ atmosphere, the oxygen concentration is $37 \%$ corresponding to the condition A3. The unit scale bar reflects the intensity of the OH signal, which has been normalized.

contrary, when the vortex breaks away from the flame, the flame interacts more closely with each other, making the flame shorter, which represents the position of maximum $\mathrm{OH}$ intensity appears near the nozzle. Therefore, the flame intensity fluctuates along the direction of the airflow in the turbulent combustion. To our knowledge, the cumulative average method is frequently applied to deal with the issues related to turbulent combustion, especially turbulent burning speed and flame brush [28]. However, when involving in the combustion field instability, several problems come with it. Typically, the cumulative average method will erase the flame transient information, so the fluctuation of the flame in the combustion field cannot be learned. The information of flame fluctuation is of significance in evaluating the performance of industrial burner.

The maximum $\mathrm{OH}$ positions from the burner exit were extracted according to the time-resolved sequences of $\mathrm{OH}$ -
PLIF images under the three experiment conditions, as is shown in Figure 4(a). It can be seen the fluctuation area satisfies a certain range and better consistency, and then the statistical method is applied to study the oscillating data. In Figure 4(b), the probability density distribution is shown to illustrate the oscillating correlation. In the $\mathrm{O}_{2} / \mathrm{N}_{2}$ atmosphere, there exist two oscillating peaks in the probability density distribution. The phenomenon of two peaks explained the leading flame mainly distributed in these two regions. In the $\mathrm{O}_{2} / \mathrm{CO}_{2}$ atmosphere, the oxygen concentration kept the same as the former. The results showed that two oscillating peaks still existed, while the peak away from the burner exit got weak. It should be noted that the oscillating peaks moved away from the burner exit, meaning that the center of combustion may move to the rear of the combustion chamber. The substitution of $\mathrm{N}_{2}$ with $\mathrm{CO}_{2}$ in the oxidizer with the same oxygen concentration resulted in an 


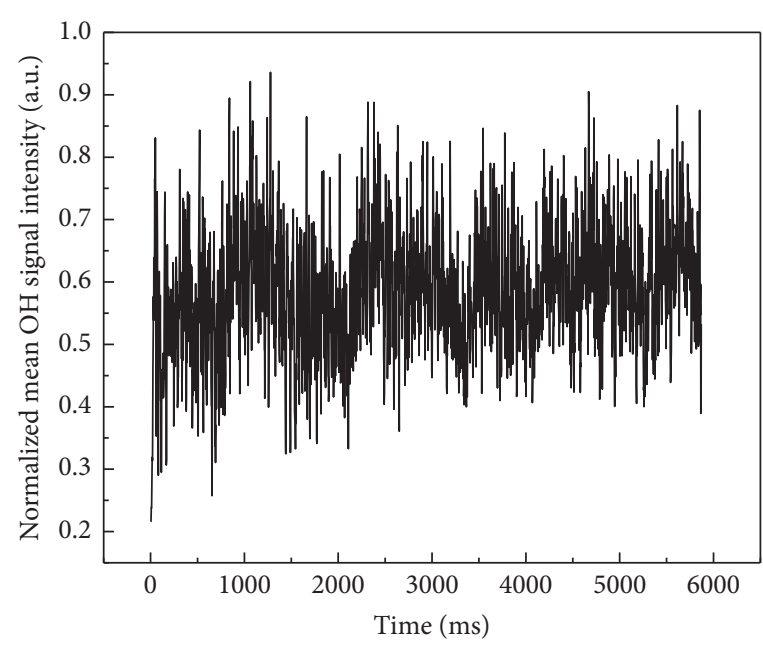

$-\mathrm{A} 1$

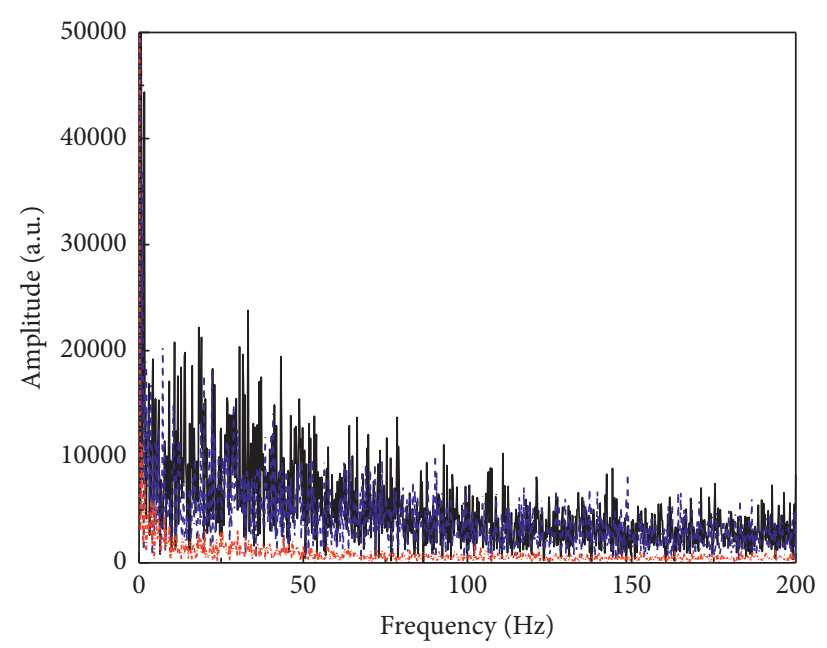

- A1

... A2

…... A3

(a)

(b)

Figure 3: Oscillation curves of the normalized mean $\mathrm{OH}$ intensity. (a) Time-domain distribution of OH intensity. More than 2400 data are acquired, and the time interval is $2.5 \mathrm{~ms}$. (b) Frequency-domain distribution of $\mathrm{OH}$ signals.

increase in the distance between the two peaks, corresponding to a more severe fluctuation of combustion center. The results also illustrated the expanding combustion zone in the $\mathrm{O}_{2} / \mathrm{CO}_{2}$ atmosphere. As the oxygen increased (up to $37 \%)$, surprisingly, the phenomenon of two oscillating peaks disappeared and the position of intense burning distributed more concentrated. In other words, the fluctuation degree of combustion center is weaker than before.

The temperature distributions across the central axis are shown in Figure 5(a), already studied by Wang et al. [7]. In the $\mathrm{O}_{2} / \mathrm{CO}_{2}$ atmosphere, the temperature field distribution changed and the high temperature area was far from the burner exit compared with the $\mathrm{O}_{2} / \mathrm{N}_{2}$ atmosphere. However, the reaction zone represented by $\mathrm{OH}$ concentration did not change when $\mathrm{CO}_{2}$ was used to replace $\mathrm{N}_{2}$ in the oxidizer as shown in Figure 5(b). The reasons can be explained that $\mathrm{CO}_{2}$ changed the temperature distributions by influencing the transport and thermal properties of the mixture rather than directly participating in chemical reactions [29]. As the oxygen increased, the highest temperature positions moved towards the burner exit and the temperature conditions tended to be similar to that of the $\mathrm{O}_{2} / \mathrm{N}_{2}$ atmosphere at low oxygen concentration. However, the reaction zone was not moving in the direction of the high temperature zone, but similarly away from the burner exit. It was shown that the reaction zone represented by $\mathrm{OH}$ concentration deviated from the high temperature zone, which is necessary to understand deeply the combustion state of the boiler.

Due to the high spatial and temporal resolutions of the PLIF measurement system, the field of view is divided into 10 regions along the direction of the airflow as shown in Figure 6(a). The aim of region segmentation is to study the combustion fluctuation of inner regions. As previously studied, the displacement velocity of the flame surface is about $4 \mathrm{~m} / \mathrm{s}$. The time interval is $2.5 \mathrm{~ms}$, so the divided area is enough to capture a full flame surface at a certain time with sufficient precision. Taking the region $\mathrm{F}$ in Figure 6(a) as an example, the mean value of the $\mathrm{OH}$ signal in this region was selected during the whole combustion process, and then the fluctuation samples of the $\mathrm{OH}$ signal value were obtained, which reflected the combustion condition in this region. The probability density distribution of statistical samples was calculated. In Figure 6(b), the correlation coefficient of Gaussian fitting is above 0.99. The half height width, i.e., FWHM, was selected to quantitatively represent the fluctuation of the combustion field. In other words, it can also reflect the fluctuation of temperature field because of $\mathrm{OH}$ intensity change. In addition, the value of $X_{C}$ in the Gaussian curve represents the $x$-coordinate of the peak position, which reflects the center of fluctuation and it can quantitatively express the intensity of the combustion.

In Figure $7(\mathrm{a})$, the $\mathrm{OH}$ signal expresses a narrow distribution and a high amplitude near the nozzle region. Besides, the $\mathrm{OH}$ signal increases along the direction of airflow, indicating that it is getting closer to the area of intense combustion. The combustion field presents a strong center and weak sides. In Figure $7(\mathrm{~b}), \mathrm{CO}_{2}$ replaces $\mathrm{N}_{2}$ in the air as the diluent. It showed that the substitution of $\mathrm{N}_{2}$ with $\mathrm{CO}_{2}$ in the oxidizer would change the combustion distribution, in which the combustion near the nozzle burned more intensely. Because of different thermodynamic properties between $\mathrm{N}_{2}$ and $\mathrm{CO}_{2}$, the diffusion rate of $\mathrm{O}_{2}$ in $\mathrm{CO}_{2}$ was lower than that in $\mathrm{N}_{2}[29,30]$. The variation of thermal and transport properties may result in a different flame distribution in the combustion chamber. It is worth noting that the distribution of the $\mathrm{OH}$ signal is more compact between regions, possessing a high degree of similarity, as shown in Figure $7(\mathrm{c})$. As the oxygen 


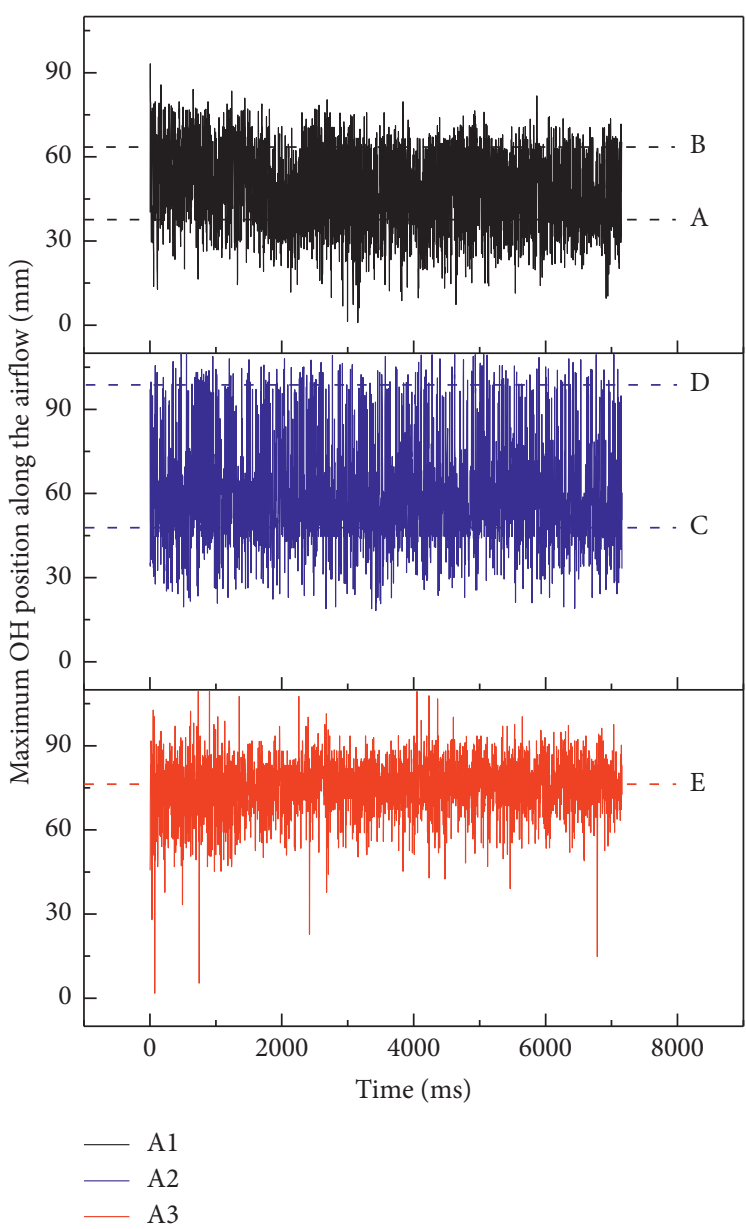

(a)

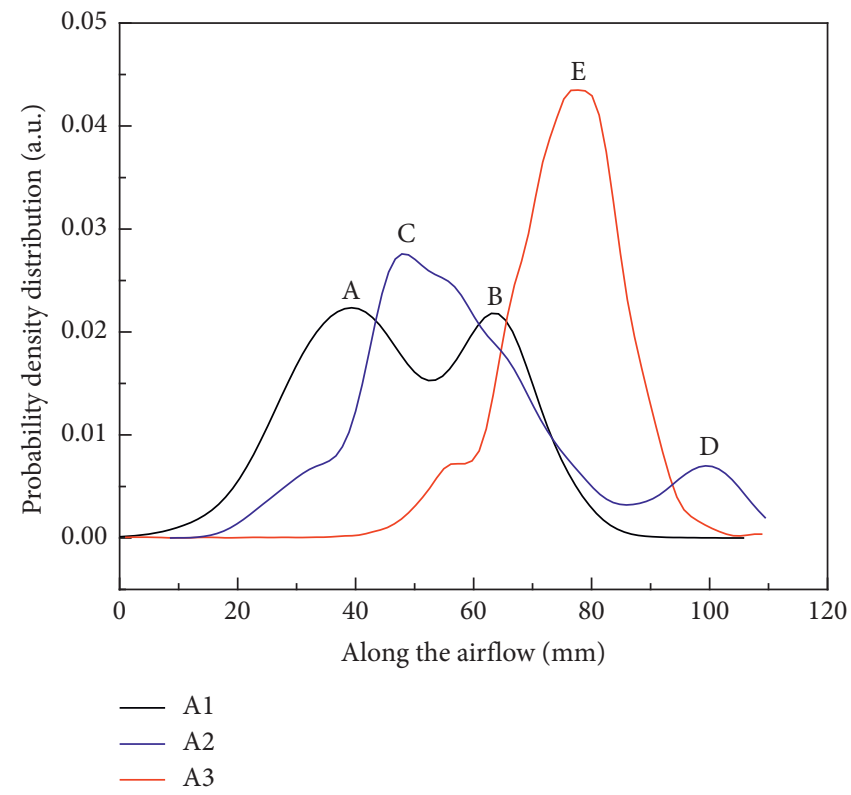

(b)

FIGURE 4: (a) Oscillation curves of the strongest burning position under three oxy-fuel conditions. The dash indicates the peak position of probability density distribution. (b) Probability density distribution of the oscillation data. A-E express the oscillation peaks.

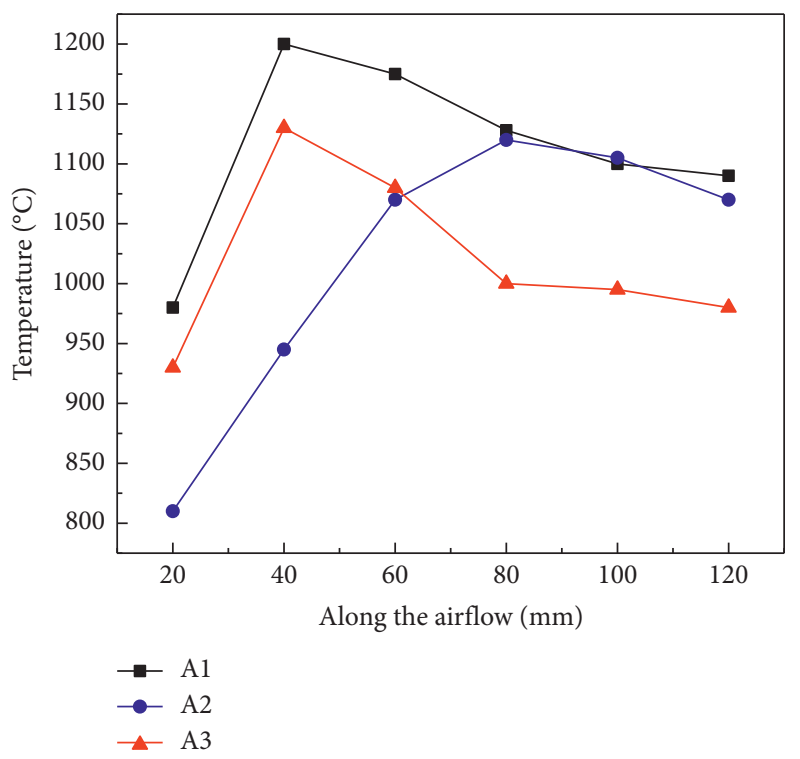

(a)

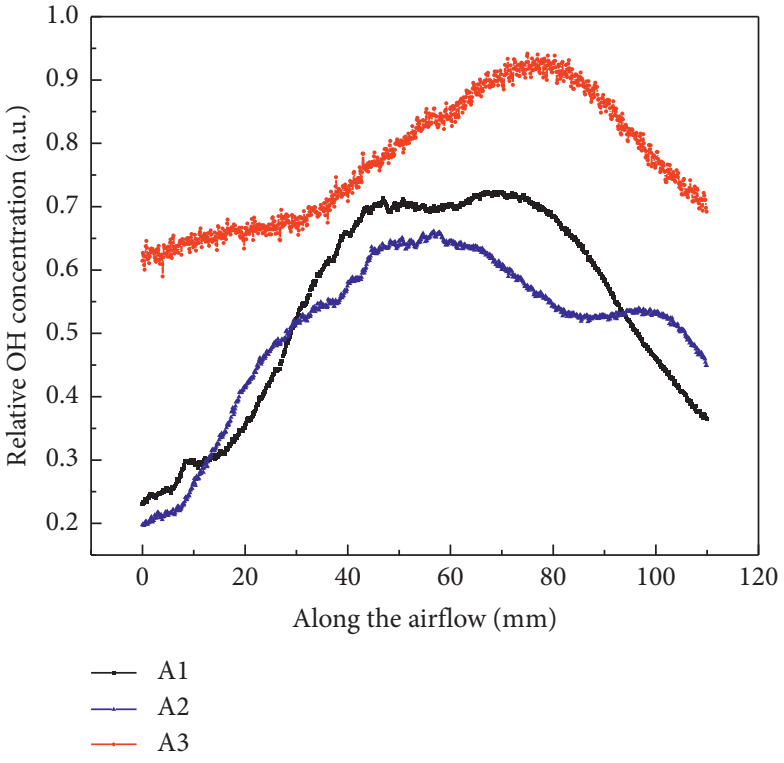

(b)

Figure 5: (a) Temperature distributions across the central axis; (b) distribution of relative $\mathrm{OH}$ concentration along the airflow. 


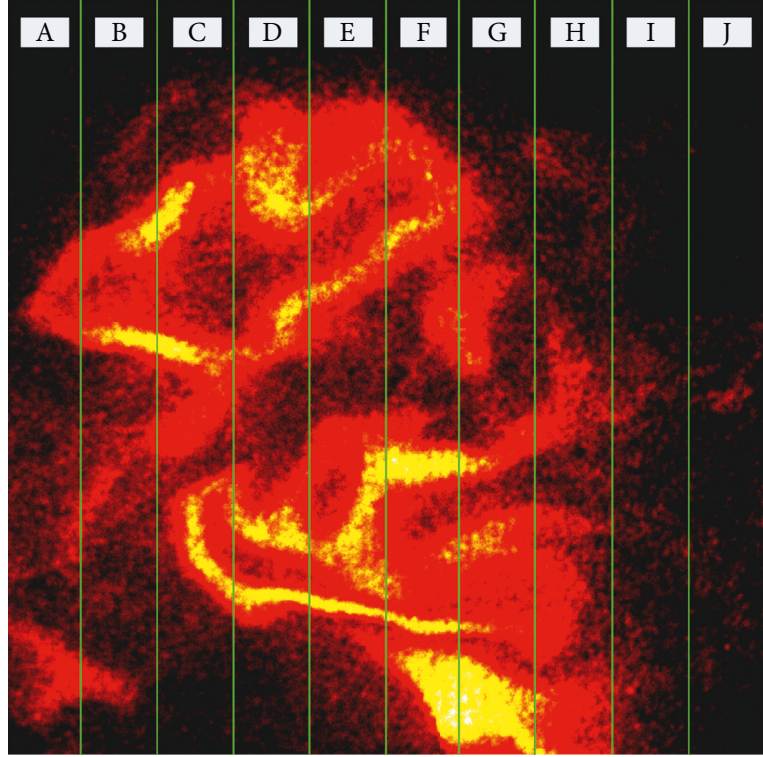

(a)

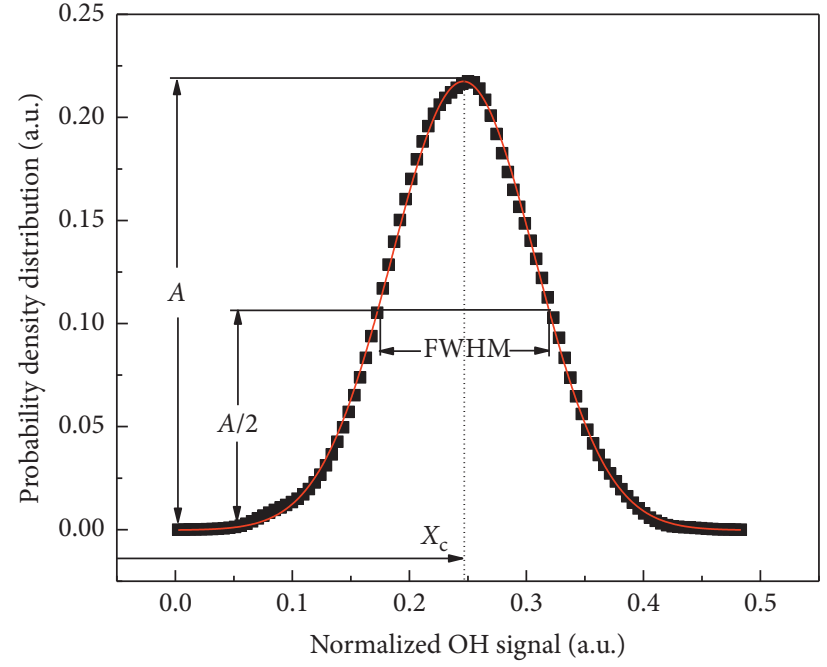

- Region $\mathrm{F}$

Gauss fit $R^{2}=0.99$

FIgURE 6: (a) Region segmentation diagram, field of view $=110 \mathrm{~mm} \times 110 \mathrm{~mm}$. The airflow is from the right to left. The nozzle is on the right. (b) Probability density distribution of oscillation data of the F region.

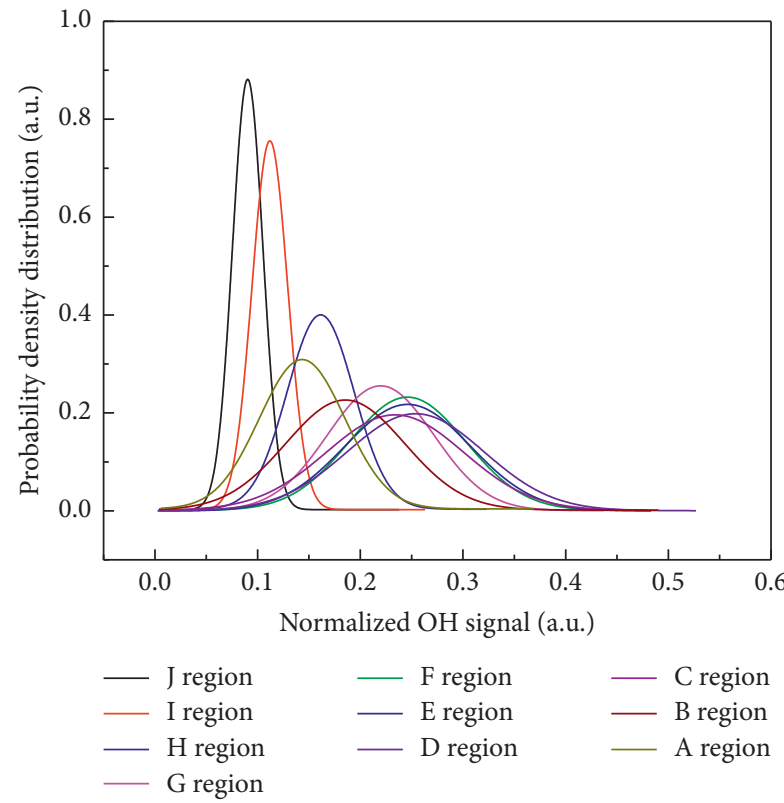

(a)

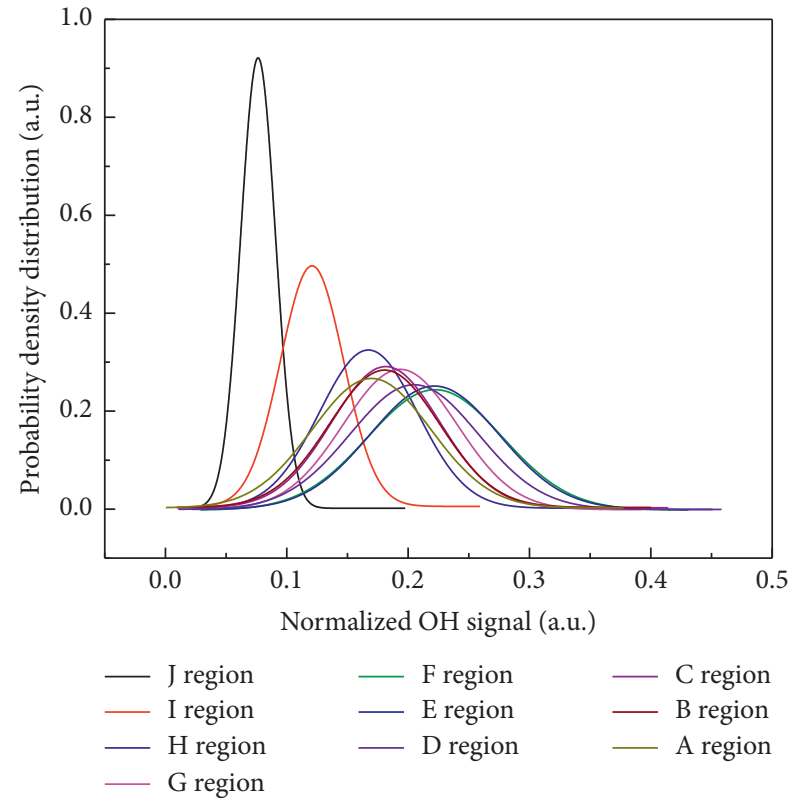

(b)

FIGURE 7: Continued. 


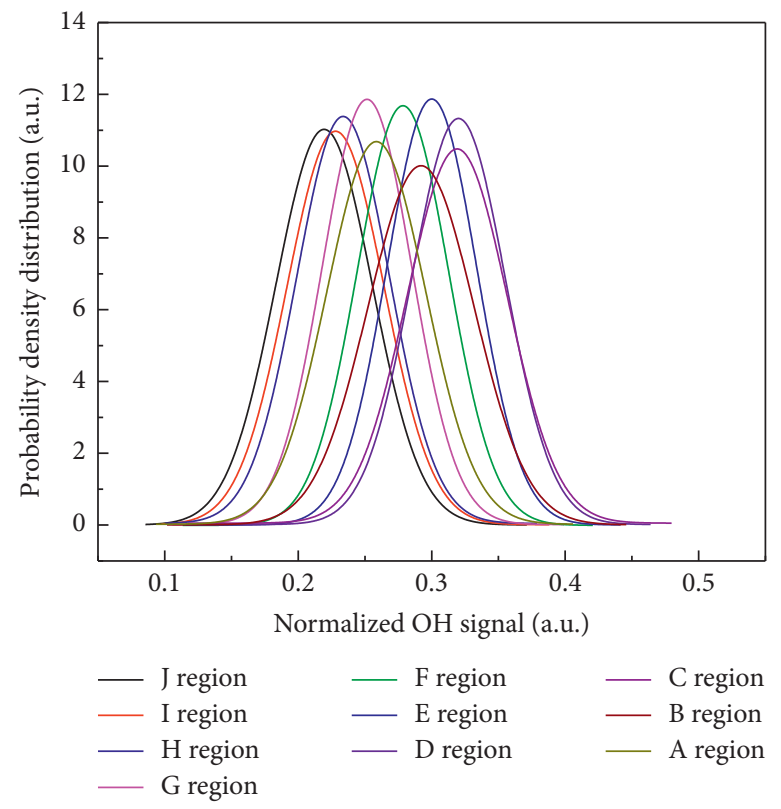

(c)

Figure 7: Probability density distribution of oscillation data of various regions, corresponding to the conditions (a) A1, (b) A2, and (c) A3.

concentration increases, the temperature of the reaction gas rises, which compensates for temperature reduction due to low diffusivity.

In order to intuitively reflect the interregional fluctuation conditions, the values of FWHM in ten regions above were extracted along the airflow, as shown in Figure 8. The behavior of the global flame is controlled by the local flame. The fluctuation of inner regions is caused by the intensity change of the local flame in the inner region, so the local fluctuation information is beneficial to understand the global flame behavior deeply. It can be seen the value of FWHM increases first and then decreases in the $\mathrm{O}_{2} / \mathrm{N}_{2}$ atmosphere, corresponding to the fluctuation of temperature. Besides, the peak is behind the field of view, namely, away from the nozzle direction. In the $\mathrm{O}_{2} / \mathrm{CO}_{2}$ atmosphere, the peak gradually moves to the nozzle and the value of FWHM decreases slightly. In other words, the degree of temperature fluctuation in the $\mathrm{O}_{2} / \mathrm{CO}_{2}$ atmosphere was not as violent as the former. With the $\mathrm{O}_{2}$ concentration increasing, up to 37 percent, it can be found that a nearly constant FWHM value was presented, which means fluctuation differences between regions are weak.

According to the change trend of the $X_{C}$ value in Figure 9, good agreement was obtained for the center of fluctuation of both $\mathrm{N}_{2}$ diluent and $\mathrm{CO}_{2}$ diluent, meaning that the substitution of $\mathrm{N}_{2}$ with $\mathrm{CO}_{2}$ in the oxidizer with the same oxygen concentration would not significantly change the center of fluctuation. A comparison of 33 percent $\mathrm{O}_{2}$ concentration and 37 percent $\mathrm{O}_{2}$ concentration in the $\mathrm{O}_{2} / \mathrm{CO}_{2}$ atmosphere obviously illustrates that the latter greatly is superior to the former. Analysis of the image suggests that the $\mathrm{O}_{2}$ concentration plays a role in the intensity of the combustion, while the diluent characteristic has no obvious effect. The soot in the reference case with higher oxygen concentration participates

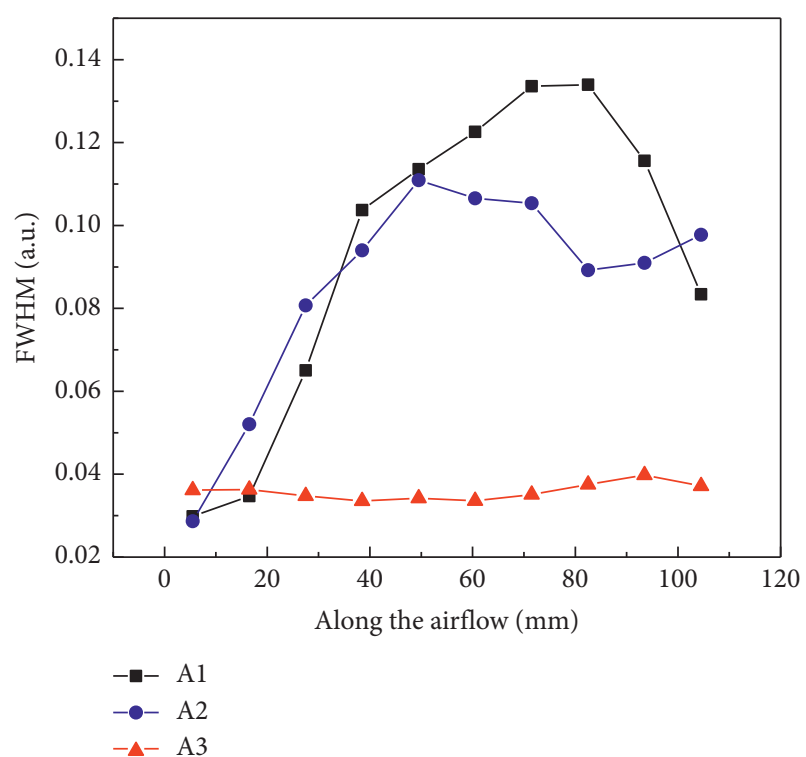

FIGURE 8: FWHM data of three oxy-fuel conditions in different regions.

in the radiation heat transfer, causing a higher temperature level in the whole combustion chamber [17]. In terms of combustion fluctuation, both the $\mathrm{O}_{2}$ concentration and the diluent characteristic contribute to it. In addition, it can be found that the distribution of fluctuation center of the inner region is consistent with the results representing overall combustion intensity shown in Figure 5(b).

It is true that $\mathrm{CO}_{2}$ could inhibit combustion to some extent; besides, it is superior to $\mathrm{N}_{2}$ in maintaining combustion zone stability. On the contrary, as the $\mathrm{O}_{2}$ concentration increased, more intensely combustion could be 


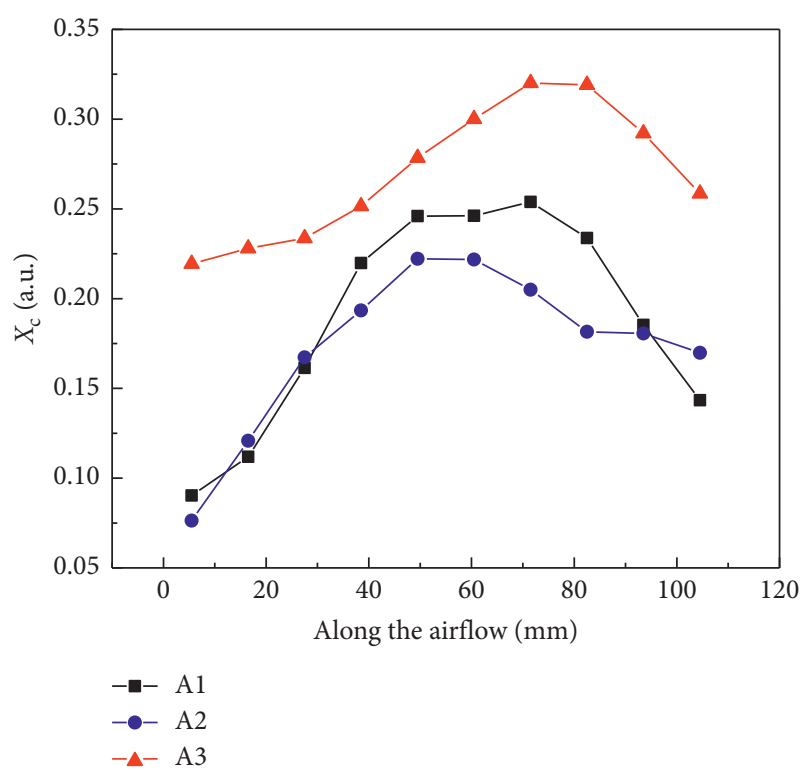

Figure 9: $X_{\mathrm{C}}$ data of three oxy-fuel conditions in different regions.

found; meanwhile, the stability of combustion region was significantly improved.

\section{Conclusions}

The flame structures of oxy-fuel combustion in the heavy oil boiler using $400 \mathrm{~Hz}$ OH-PLIF have been investigated in the present work. The phenomenon of stratified flame combustion is related to the characteristic of flame oscillation. Low-frequency oscillation of the flame can be found in the oxy-fuel combustion of heavy oil, although the frequency characteristic disappeared with higher $\mathrm{O}_{2}$ concentration (up to 37 percent). Interregional combustion instabilities were demonstrated by the statistical probability density method; besides, the values of FWHM and $X_{C}$ were extracted to quantitatively demonstrate the combustion fluctuation. The fluctuation of combustion center was affected by the type of diluent and the concentration of oxygen. The bimodal oscillation of the combustion center was demonstrated; $\mathrm{CO}_{2}$ played a role in the extension of the combustion center. The fluctuation degree of the combustion region reflected by the value of FWHM expressed strong center and weak sides. Furthermore, by analyzing the change in $X_{\mathrm{C}}$ values, $\mathrm{CO}_{2}$ could inhibit combustion and reject combustion instability to some extent. When it comes to the effect of oxygen concentration on combustion instability, it can be found that the combustion was obviously improved and the fluctuation differences of the inner region were greatly reduced.

In further study, the improvement of laser repetition frequency is of significance in investigating combustion instability with higher precision. Compared with traditional measurement methods, PLIF technology has great advantages in evaluating burner performance.

\section{Data Availability}

The data used to support the findings of this study are available from the corresponding author upon request.

\section{Conflicts of Interest}

The authors declare that they have no conflicts of interest.

\section{Acknowledgments}

This work was supported by the National Natural Science Foundation of China (Grant nos. 51536002, 61405048, and 91441130), the Fundamental Research Funds for the Central Universities (Grant no. HIT.NSRIF.2014045), and the National Key Scientific Instrument and Equipment Development Projects of China (Grant no. 2012YQ040164).

\section{References}

[1] F. J. Hein, "Geology of bitumen and heavy oil: an overview," Journal of Petroleum Science and Engineering, vol. 154, pp. 551-563, 2017.

[2] Q. Zhang, H. Huang, L. Zheng, and J. Qin, "Secondary hydrocarbon generation potential from heavy oil, oil sand and solid bitumen during the artificial maturation," Organic Geochemistry, vol. 38, no. 12, pp. 2024-2035, 2007.

[3] M. Dong, S. Ma, and Q. Liu, "Enhanced heavy oil recovery through interfacial instability: a study of chemical flooding for Brintnell heavy oil," Fuel, vol. 88, no. 6, pp. 1049-1056, 2009.

[4] F. Carrasco-Maldonado, R. Spörl, K. Fleiger, V. Hoenig, J. Maier, and G. Scheffknecht, "Oxy-fuel combustion technology for cement production-state of the art research and technology development," International Journal of Greenhouse Gas Control, vol. 45, pp. 189-199, 2016.

[5] M. V. Gil, J. Riaza, L. Álvarez, C. Pevida, J. J. Pis, and F. Rubiera, "Oxy-fuel combustion kinetics and morphology of coal chars obtained in $\mathrm{N}_{2}$ and $\mathrm{CO}_{2}$ atmospheres in an entrained flow reactor," Applied Energy, vol. 91, no. 1, pp. 67-74, 2012.

[6] P. Glarborg and L. L. B. Bentzen, "Chemical effects of a high $\mathrm{CO}_{2}$ concentration in oxy-fuel combustion of methane," Energy \& Fuels, vol. 22, no. 1, pp. 291-296, 2008.

[7] Z. Wang, M. Liu, X. Cheng, Y. He, Y. Hu, and C. Ma, "Experimental study on oxy-fuel combustion of heavy oil," International Journal of Hydrogen Energy, vol. 42, no. 31, pp. 20306-20315, 2017.

[8] C. Külsheimer and H. Büchner, "Combustion dynamics of turbulent swirling flames," Combust and Flame, vol. 131, no. 1-2, pp. 70-84, 2002.

[9] J.-Y. Choi, F. Ma, and V. Yang, "Combustion oscillations in a scramjet engine combustor with transverse fuel injection," Proceedings of the Combustion Institute, vol. 30, no. 2, pp. 2851-2858, 2005.

[10] K. H. Yu, A. Trouvé, and J. W. Daily, "Low-frequency pressure oscillations in a model ramjet combustor," Journal of Fluid Mechanics, vol. 232, pp. 47-72, 1991.

[11] H. Wang, M. Sun, N. Qin, H. Wu, and Z. Wang, "Characteristics of oscillations in supersonic open cavity flows," Flow, Turbulence and Combustion, vol. 90, no. 1, pp. 121-142, 2013.

[12] M.-B. Sun, H. Geng, J.-H. Liang, and Z.-G. Wang, "Flame characteristics in supersonic combustor with hydrogen 
injection upstream of cavity flameholder," Journal of Propulsion and Power, vol. 24, no. 4, pp. 688-696, 2008.

[13] M. C. Lee, S. B. Seo, J. Yoon, M. Kim, and Y. Yoon, "Experimental study on the effect of $\mathrm{N}_{2}, \mathrm{CO}_{2}$, and steam dilution on the combustion performance of $\mathrm{H}_{2}$ and $\mathrm{CO}$ synthetic gas in an industrial gas turbine," Fuel, vol. 102, pp. 431-438, 2012.

[14] K.-C. Lin, K. Jackson, R. Behdadnia, T. A. Jackson, F. Ma, and V. Yang, "Acoustic characterization of an ethylene-fueled scramjet combustor with a cavity flameholder," Journal of Propulsion and Power, vol. 26, no. 6, pp. 1161-1170, 2010.

[15] Z.-G. Wang, M.-B. Sun, H.-B. Wang, J.-F. Yu, J.-H. Liang, and F.-C. Zhuang, "Mixing-related low frequency oscillation of combustion in an ethylene-fueled supersonic combustor," Proceedings of the Combustion Institute, vol. 35, no. 2, pp. 2137-2144, 2015.

[16] M. B. Sun, C. Gong, S. P. Zhang, J. H. Liang, W. D. Liu, and Z. G. Wang, "Spark ignition process in a scramjet combustor fueled by hydrogen and equipped with multi-cavities at Mach 4 flight condition," Experimental Thermal and Fluid Science, vol. 43, pp. 90-96, 2012.

[17] G.-N. Li, H. Zhou, and K.-F. Cen, "Emission characteristics and combustion instabilities in an oxy-fuel swirl-stabilized combustor," Journal of Zhejiang University-Science A, vol. 9, no. 11, pp. 1582-1589, 2008.

[18] W. Huang, W.-D. Liu, S.-B. Li, Z.-X. Xia, J. Liu, and Z.-G. Wang, "Influences of the turbulence model and the slot width on the transverse slot injection flow field in supersonic flows," Acta Astronautica, vol. 73, pp. 1-9, 2012.

[19] M. Versluis, N. Georgiev, L. Martinsson, M. Aldén, and S. Kröll, "2-D absolute $\mathrm{OH}$ concentration profiles in atmospheric flames using planar LIF in a bi-directional laser beam configuration," Applied Physics B: Lasers and Optics, vol. 65, no. 3, pp. 411-417, 1997.

[20] J. H. Frank, P. M. Kalt, and R. W. Bilger, "Measurements of conditional velocities in turbulent premixed flames by simultaneous OH PLIF and PIV," Combustion and Flame, vol. 116, no. 1-2, pp. 220-232, 1999.

[21] M. Bruchhausen, F. Guillard, and F. Lemoine, "Instantaneous measurement of two-dimensional temperature distributions by means of two-color planar laser induced fluorescence (PLIF)," Experiments in Fluids, vol. 38, no. 1, pp. 123-131, 2005.

[22] J. Kiefer, Z. S. Li, J. Zetterberg, X. S. Bai, and M. Aldén, "Investigation of local flame structures and statistics in partially premixed turbulent jet flames using simultaneous singleshot $\mathrm{CH}$ and $\mathrm{OH}$ planar laser-induced fluorescence imaging," Combustion and Flame, vol. 154, no. 4, pp. 802-818, 2008.

[23] Z. S. Li, B. Li, Z. W. Sun, X. S. Bai, and M. Aldén, "Turbulence and combustion interaction: high resolution local flame front structure visualization using simultaneous single-shot PLIF imaging of $\mathrm{CH}, \mathrm{OH}$, and $\mathrm{CH}_{2} \mathrm{O}$ in a piloted premixed jet flame," Combustion and Flame, vol. 157, no. 6, pp. 1087-1096, 2010.

[24] C. Yang, J. Peng, X. Yu et al., "Continuous $100 \mathrm{~Hz}$ planar laser-induced fluorescence applied to the study of combustion processes," Spectroscopy Letters, vol. 50, no. 5, pp. 265-269, 2017.

[25] H. Wang, Z. Wang, M. Sun, and H. Wu, "Combustion modes of hydrogen jet combustion in a cavity-based supersonic combustor," International Journal of Hydrogen Energy, vol. 38, no. 27, pp. 12078-12089, 2013.

[26] J. Peng, Z. Cao, X. Yu, Y. Yu, G. Chang, and Z. Wang, "Investigation of flame evolution in heavy oil boiler bench using high-speed planar laser-induced fluorescence imaging," Applied Sciences, vol. 8, no. 9, pp. 1691-1701, 2018.

[27] M. Juddoo and A. R. Masri, "High-speed OH-PLIF imaging of extinction and re-ignition in non-premixed flames with various levels of oxygenation," Combustion and Flame, vol. 158, no. 5, pp. 902-914, 2011.

[28] I. G. Shepherd and R. K. Cheng, "The burning rate of premixed flames in moderate and intense turbulence," Combustion and Flame, vol. 127, no. 3, pp. 2066-2075, 2001.

[29] F. Liu, H. Guo, and G. J. Smallwood, "The chemical effect of $\mathrm{CO}_{2}$ replacement of $\mathrm{N}_{2}$ in air on the burning velocity of $\mathrm{CH}_{4}$ and $\mathrm{H}_{2}$ premixed flames," Combustion and Flame, vol. 133, no. 4, pp. 495-497, 2003.

[30] Y. Xie, J. Wang, M. Zhang, J. Gong, W. Jin, and Z. Huang, "Experimental and numerical study on laminar flame characteristics of methane oxy-fuel mixtures highly diluted with $\mathrm{CO}_{2}$," Energy \& Fuels, vol. 27, no. 10, pp. 6231-6237, 2013. 

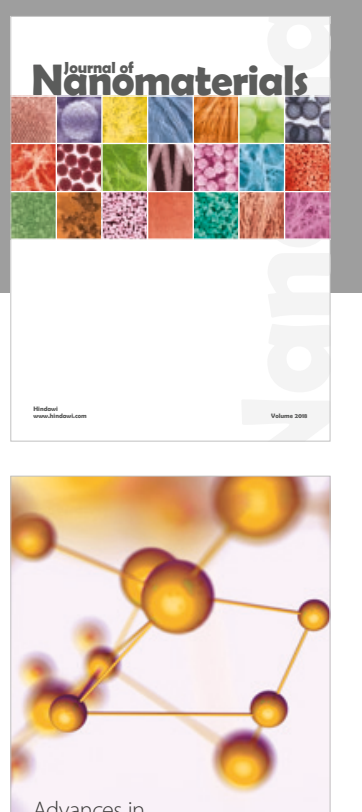

Physical Chemistry
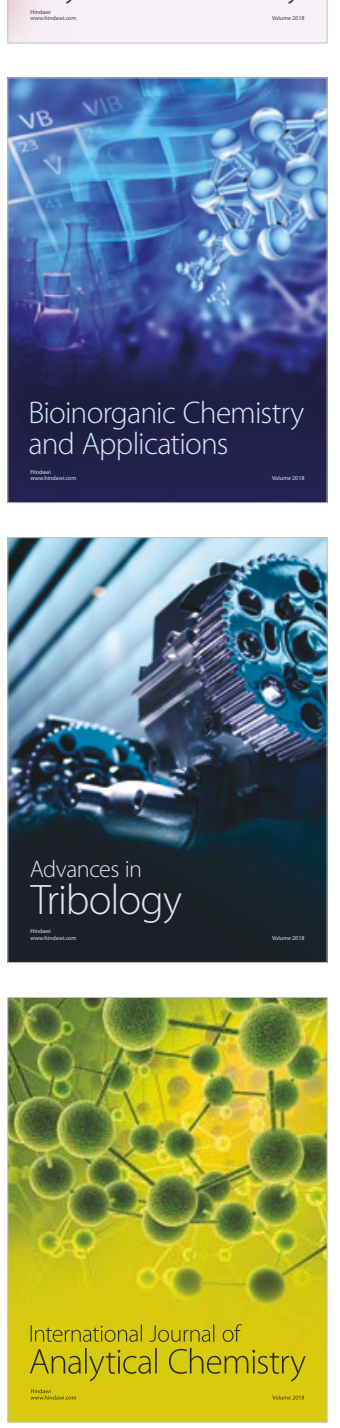

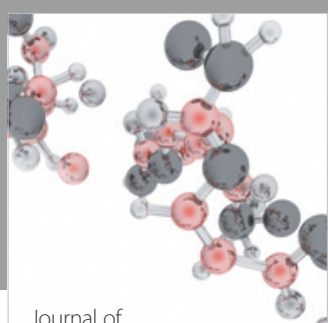

Analytical Methods

in Chemistry

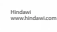

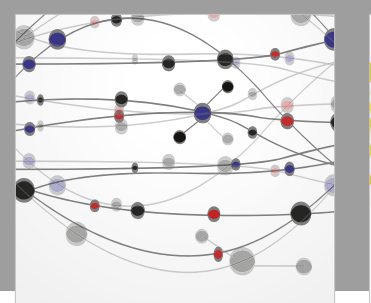

The Scientific World Journal

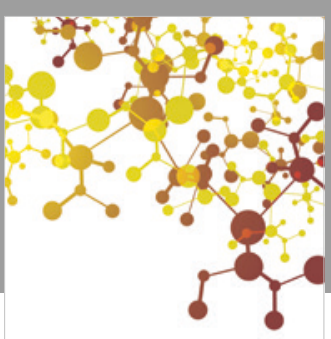

Journal of

Applied Chemistry
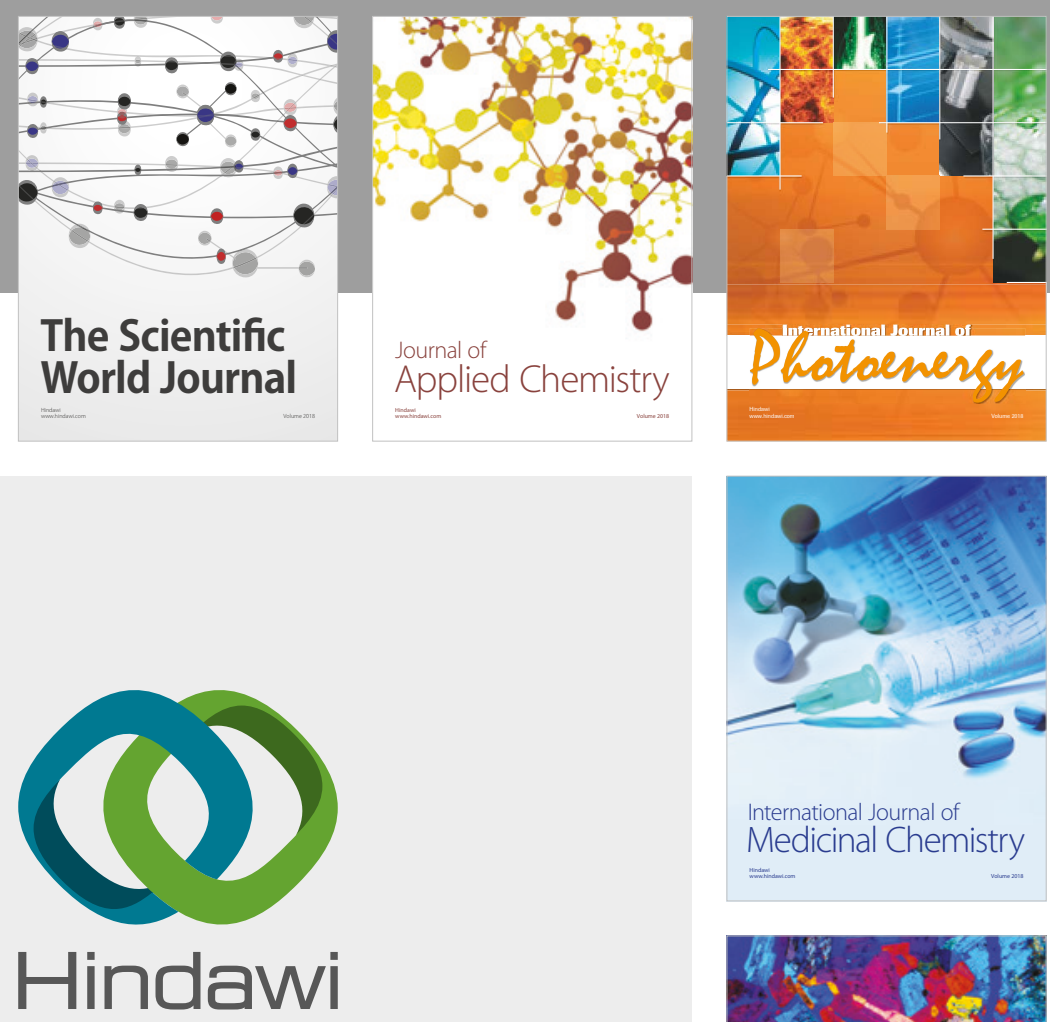

Submit your manuscripts at

www.hindawi.com
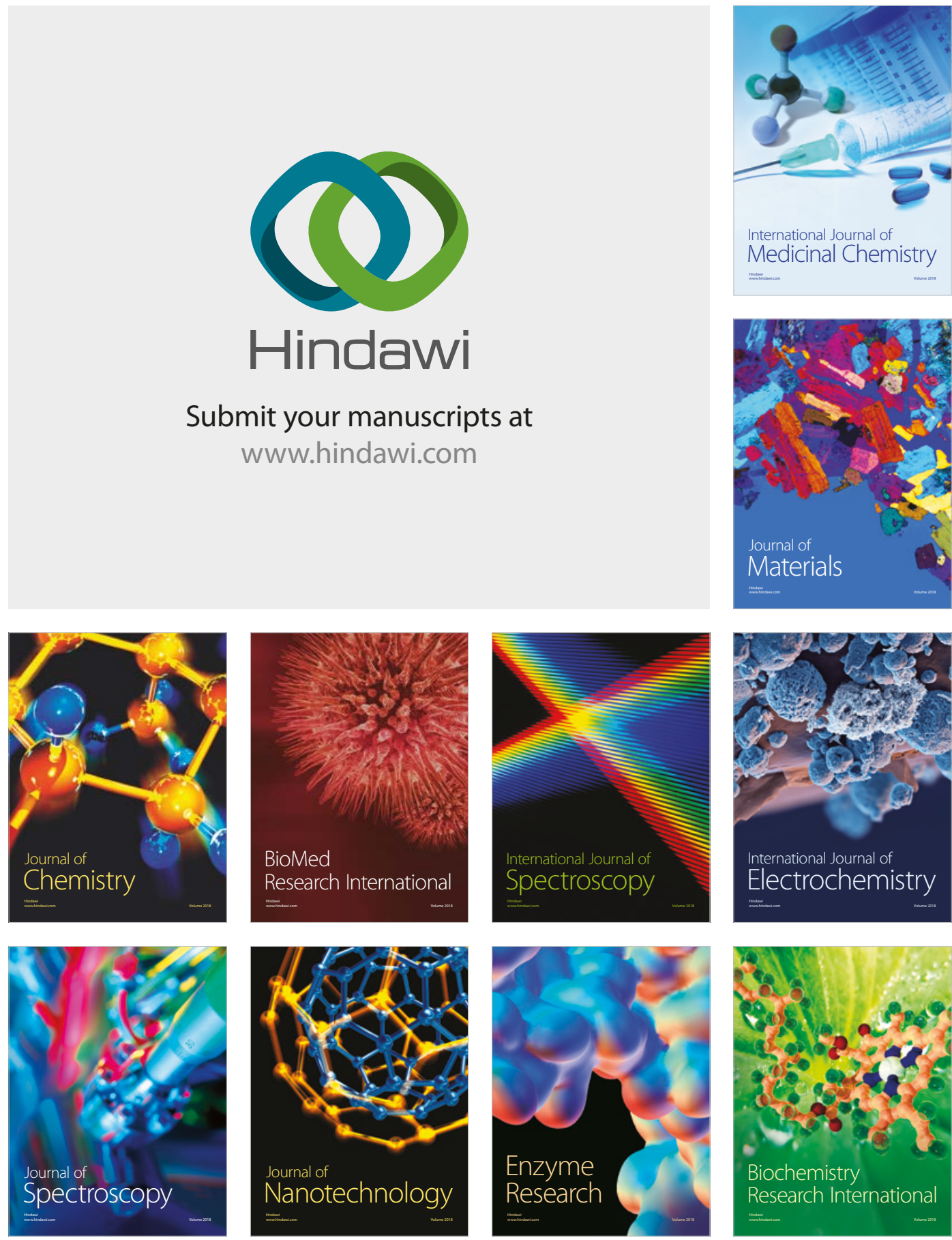
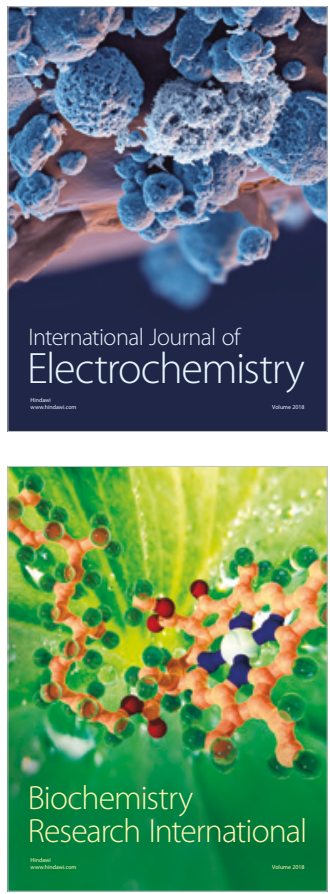